\title{
Lights! Camera! Action! \\ Exploring Links between Inclusive Teaching in Broadcast Education and Diversity in Canadian Media
}

\author{
Anna Augusto Rodrigues \\ Durham College
}

\begin{abstract}
Inclusive classrooms are spaces where opinions are valued, viewpoints are expressed without fear and the course content allows learners to be exposed to a multitude of perspectives [1]. This mixedmethods research project examined the inclusive teaching practices of broadcast educators from different institutions across Canada. As well, broadcast professionals from diverse backgrounds were interviewed on their broadcast educations in Canada and their perspectives on the Canadian media industry in terms of diversity. The findings from this small research project suggest that broadcast educators are incorporating inclusive techniques in their classrooms, however, the broadcast professionals interviewed felt that more could be done to provide inclusive learning environments in broadcast education. Both broadcast educators and broadcast professionals felt that inclusive teaching has positive impacts on the media industry in Canada in terms of diversity.
\end{abstract}

\section{Introduction}

For the past eight years I have taught courses related to journalism and broadcasting at Durham College, a community college located in Oshawa, Ontario, Canada. My teaching experience in this area comes from working in the television news industry for over a decade in Toronto, considered Canada's largest media market. In the field of broadcast education, instructors use videos, audio files, case studies and other materials to augment instruction, however, when looking at my own teaching practices, I realized the materials I use in the classroom do not represent the diversity of Canada's population.

Canada has one of the most diverse societies in the world. According to the 2011 National Household Survey (the national census), Canada has a growing population of immigrants, an increasing number of Canadian-born people with an ethnocultural background and an aboriginal community that has increased substantially in the past few years. The survey also indicates that the number of religions being practiced and languages being spoken in Canada has increased as well since the last census [2]. Two national surveys conducted in 2012 by Forum Research Inc. (commissioned by the National Post, a national newspaper) indicated that five per cent of Canadians identified as being gay, lesbian, bisexual or transgender [3]. Approximately seven per cent of students in post-secondary education reported having a disability, which is half of the number of Canadians who identify as having a disability according to a 2011 report by the Higher Education Quality Council of Ontario [4]. According to data collected from Statistics Canada, there are more women enrolled in college and university programs than men and higher numbers of females graduating from post-secondary programs than males. The data also indicates that two out of three graduates in Communication programs in Canada are women [5].

These statistics are snapshots of Canadian society providing the reason for one of the codes in Canada's Broadcasting Act, which is to ensure that the diverse nature of Canadian society is represented equally and in a positive manner in the media [6]. However, a literature review revealed that research in this area points to a very different representation of Canadians being broadcast in traditional media. The above information and an audit of my own teaching practices led me to consider if there are causal links between the lack of diversity in Canadian media and the manner broadcasting is taught at colleges and universities. As a result, this research project was developed and put into action in an attempt to understand the following questions:

1. Are broadcast educators creating inclusive learning environments in their classrooms?

2. How might inclusive teaching in broadcast education influence diversity in Canadian media?

\section{Literature Review}

\subsection{Inclusive teaching in post-secondary education}

After an extensive literature review I was unable to locate a report or paper on the use of inclusive 
teaching practices specific to broadcast education but there are a number of articles discussing the impact inclusive teaching practices have in classrooms at the postsecondary level.

Inclusive teaching practices are teaching approaches that take into account students' genders, sociocultural identities, sexualities, religions, ethnicities, socioeconomic statuses and disabilities [1]. Studies have found that inclusive teaching has many benefits for not only the students, but also for those facilitating learning. As well, the importance of fostering an inclusive environment in classrooms was stressed frequently in the research done in this area [7] [8] [9]. Studies found that when counterhegemonic opinions are valued, viewpoints are expressed without fear, and the course content allows learners to be exposed to a multitude of perspectives, classrooms transform into educational spaces that nurture the growth of students, not only in their areas of study, but also as global citizens, resulting in students who do better academically [1] [7]. Different techniques have been and are being employed in post-secondary instruction to reach the diverse student population, such as digital storytelling, as instructors realize the importance of creating such opportunities in the classroom [1] [8]. Furthermore, Schwieger, Gros and Barberain state that educators should not only look upon a diverse student body as an opportunity to teach about tolerance and respect, but that they should regard understanding diversity as a necessary component in their day-to-day teaching practices [9].

\subsection{Diversity in Canadian Media}

Diversity in media refers to providing fair, balanced and accurate representations of individuals or groups of people, regardless of gender, sexual orientation, ethnicity, religion, age socioeconomic status and/or disability [10]. Although a number of policy initiatives related to diversity are in effect in Canada, in reality "patterns of inclusiveness have proven erratic" in Canadian media [10] [11]. For example, a 2012 report on diversity in Toronto's media production industry points out that despite the diversity initiatives from the past 30 years, not a lot of "meaningful progress has been achieved in the inclusion of visible minorities in front of and behind the camera, especially among senior decision makers in the industry, and among independent producers" [11].

MediaSmarts, a not-for-profit organization with the mandate of educating the public on matters concerning digital and media literacy, reports an unbalance in the portrayals of Canadian diversity in the media. Some of their research findings include: crimes against Aboriginal people are underreported by news media in Canada; persons with disabilities are mostly absent from mainstream media, but when they do appear as characters in a TV program or movie, the representation of the character falls into the category of being heroic or dependent on ablebodied characters; men are still predominantly used as experts in information programing, although the number of women in the fields of business, politics and economics has grown substantially in the past twenty years [12]. As well, a research paper from Media Action Média, an organization that promotes gender equity through media analysis, found that a number of primetime television programs in Canada reinforce the "heteronormative, white middle-class fantasy" [13] narrative at the expense of storylines with characters representing the nature of Canada's diverse populations [13].

\section{Research Design}

In January 2014 I began a six-month mixedmethods research project in an attempt to answer the following research questions:

\section{Are broadcast educators creating inclusive learning environments in their classrooms?}

2. How might inclusive teaching in broadcast education influence diversity in Canadian media?

This research project has two components. Firstly, broadcast educators were surveyed through an online survey. The survey was posted online using FluidSurveys, a survey software company that is Canadian. Participants had three questions and 11 statements to complete. Each statement could be rated using a Likert scale model with the following options: strongly agree, agree, neither agree nor disagree, strongly disagree and not applicable. Participants had the option of not answering a question or statement and still continuing with the survey. As well, the survey was 100 per cent anonymous as no identifying markers were collected from responses. Participants were made aware of all of this information through a Letter of Consent that was posted before the survey launched. Broadcast educators were also interviewed using a semistructured method via phone or e-mail.

To capture a national view of inclusive teaching in broadcast education across Canada, I applied for Research Ethics review at eight different institutions with broadcasting/media programs. These institutions are located in the provinces of British Columbia, Manitoba, Ontario and Nova Scotia. I received approval from six institutions as one application was lost and not processed and another could not be reviewed within the time frame I required for my research. I sent a Letter of Information to the six institutions where approval was granted with the request that it be forwarded to all faculty, including part-time or contract instructors, teaching in the broadcasting/media 
programs. The Letter of Information outlined the objectives of the project, contained the link to the online survey and also an invitation to be interviewed on the subject along with a Letter of Consent. After the initial contact, two follow up emails were sent to each of the six institutions as reminders that participants were still being sought for this project. When the data collection period ended, there were seven completed survey responses. As well, three broadcast educators had agreed to be interviewed.

The second part of this research project involved interviewing Canadian media professionals from diverse backgrounds. These participants were asked about their experiences while taking a broadcasting/media program in Canada in terms of diversity and their backgrounds. As well, they were asked to reflect on the impact inclusive teaching practices have or could have on the representation of a diverse population in Canadian media.

The broadcast professionals who agreed to participate were only interviewed for this project and not surveyed. Some of the participants were approached after researching profiles on the social media platform LinkedIn. As well, some were identified as potential participants through former colleagues I had worked with in the media industry however all those chosen as potential participants, and subsequently interviewed, were individuals with whom I had never had a close professional or personal relationship. Once identified as a potential participant who was from a diverse background and had experienced a broadcast education in Canada, they were contacted through e-mail with information on the project and its objectives. A Letter of Information and Consent explaining the research project at length was then sent to participants open to learning more. Thirteen individuals were sent Letters of Information and Consent with eleven signing the consent letter however only eight people agreed to be interviewed for the project.

\section{Methodology and Data Analysis}

This study used a mixed-methods approach, which Johnson and Onwuegbuzie state provides a more accurate representation of the data collected, resulting in "superior research" when compared to using a one-method approach [14].

In terms of quantitative data, I was especially interested in implementing a survey for broadcast educators as an exploratory exercise to measure interest in the ideas I was proposing. As the literature review had revealed the lack of research in the area of broadcast education and inclusive teaching, I did not have any information to base this research project on so I felt a survey would be a way to introduce the topic to broadcast educators. The survey questions were related to the participants' background in teaching, such as they type of institution the individual taught at (university or community college), and the length of time the person has been teaching broadcast/media courses.

The statements dealt with the individual's knowledge of inclusive teaching practices, if techniques are being used, and the importance the participant places on using such methods in his/her classroom.

The quantitative data were analyzed manually using the reporting tool offered by the online survey software I was using. By launching that particular tool, all the data were aggregated into one document where responses were displayed in a visual format using colour-coded horizontal bars. Data were also displayed by percentage and count. The survey data was subsequently triangulated with the data from the interviews conducted with the broadcast educators.

The qualitative data collected from the interviews with the broadcast educators and the broadcast professionals, were coded and analyzed manually using Grounded Theory. This approach permits themes to be developed inductively from the collected data, allowing researchers to reach conclusions unencumbered by theoretical assumptions, thus making Grounded Theory an excellent qualitative research method when researching social phenomena [15] [16]. Using Grounded Theory's three levels of coding, I began with open coding, which allows large themes to be identified from the existent data [16]. By reading the transcripts and comparing the different quotes from the interviewees to the same questions posed to each, patterns emerged and I was able to recognize larger issues, related to the research questions, within these repetitions. From these patterns, categories of data emerged. This led to the second coding process in Grounded Theory: selective coding, a process by which the broad categories, previously identified, are reduced to fewer groupings through more detailed data comparison [16]. When there were no more categories to be found or collapsed, I moved into the theoretical stage of coding that finds the researcher considering the remaining categories and conceptualizing the main themes by returning to the data for an even closer reading [16], keeping in mind the research questions and the literature I had reviewed, as I developed these theories.

\section{Findings}

\subsection{Broadcast Educators}

To capture a more complete snapshot of inclusive teaching techniques in broadcast education, I applied for Research Ethics review at eight institutions across Canada. I received approval at six and sent my Letter of Information and Consent to the heads of 
departments for distribution amongst full time, part time and contract faculty teaching in broadcasting/media programs at those particular institutions. Seven individuals completed the survey and three individuals agreed to be interviewed.

The survey shows that all respondents work in community colleges, with the majority $(71.4 \%)$ indicating that they have been teaching broadcast/media related courses between five and 10 years. As well, the respondents indicated teaching courses in a variety of areas encompassing radio, television, web and print with some teaching in more than one area. The three broadcast educators who were interviewed are all part-time faculty. Two of the participants had been teaching for less than two years while another had over a decade of experience teaching. Two of the participants were female and one was male.

Three main themes emerged from the survey and interview data from the broadcast educators: firstly, those surveyed and interviewed are incorporating, to various degrees, inclusive teaching techniques in their classrooms and secondly, they believe that they can do more to be inclusive in their classrooms and are interested in learning how to accomplish this. The third theme is related to the nature of working in the broadcast/media industry and how teaching broadcast, which is a deadline-driven world further fuelled by stressful and long work hours, creates challenges to inclusive teaching.

The survey indicates that over 70 per cent of respondents agreed that the materials and resources that they are using for teaching are sensitive to the diverse nature of their classrooms and do not reinforce stereotypes. The survey also revealed more than half of the participants felt that their teaching practices could be more inclusive, as they felt this was an important part of their work as instructors. The data from the interviews seemed to support these findings with one participant stating, "I still think I need more skills and strategies to allow students to open up in class. "

The interviewees and those surveyed demonstrated through their answers that they seemed to believe that there was room for improvement and were open to learning more diverse teaching techniques. One participant noted that after attending a seminar on teaching practices he had been introduced to inclusive teaching and, as a result, had acquired a different lens to apply to his teaching. He said, "I am more aware and sensitive to everyone in the class, whether it be how they are learning or who they are as people. With that new mindset I am using a broader spectrum of tools to engage everyone."

The participants shared concrete examples of their inclusive teaching, such as being conscious of students who are dealing with mental health issues, creating more comfortable learning environments for students with physical disabilities and ensuring content used as examples in the classroom used inclusive language.

In relation to the third theme, an interviewee commented how the nature of broadcasting courses, where a huge amount of content is delivered in a short amount of time leading to a fast-paced, intense learning environment, could have an impact on diverse teaching in classrooms. Another interviewee stated that broadcast education specifically provides extra challenges in the area of inclusive teaching. "It is often difficult to figure out what is an inclusive issue or laziness or what is really going on with students as they rotate through positions in a highly stressful and demanding broadcasting class. It would be great if I had more time to know the students and what issues they might be dealing with, but on the other hand, when a journalist is in a newsroom setting, no one cares what they're personally dealing with - they just have to deliver so it's a balance. Also, there was so much teaching/learning to get through that it was difficult to slow down. My time was so limited".

The interviewees were asked to reflect on how inclusive teaching in broadcast education shapes the Canadian media landscape. One interviewee felt that there is a positive impact that ripples through the industry: "I would like to think so because inclusive teaching actually teaches students how to respect one another and emphasizes the important nuances we can all bring to the table, which I hope would give them an open mind when looking for story ideas and building their stories."

Another interviewee pointed to the world of broadcast still being exclusive despite some advances in that area and that more knowledge and education surrounding issues of diversity would help break down existing barriers.

\subsection{Broadcast Professionals}

Eight broadcast professionals were interviewed for the second phase of this research project. These participants were asked about their experiences while taking a broadcasting/media program in Canada in terms of diversity and their backgrounds. As well, they were asked to reflect on the impact inclusive teaching practices have or could have on the representation of a diverse population in the media industry in Canada. The interviewees were composed of four men and four women, from diverse backgrounds, who are working currently, except for one individual, in $\mathrm{TV}$, radio, web, print and some in a combination of mediums. All interviewees are graduates of broadcasting programs or broadcast journalism programs with the earliest graduating in 1982 and the most recent in 2012.

The data revealed that all interviewees, except for one individual, felt that more could be done to 
provide inclusive learning environments in classrooms teaching broadcast however two of the interviewees saw this problem being rooted in the Canadian media industry. To a lesser extent, two other themes surfaced: the issues facing women in broadcast were mentioned in several of the interviews and the lack of role models from diverse backgrounds being brought into classes was another concern identified by a few of the interviewees.

All of the broadcast professionals said that they had not experienced any deliberate discrimination while undertaking their broadcasting programs however seven individuals all mentioned examples where they felt the classroom was not inclusive at all or more could have been done in that area. One participant said that he did not feel there was any effort on the part of the instructors to divert from classroom materials that were reflective of the dominant culture, adding that introducing content showing stories from other cultures would have been a simple way to provide a more inclusive classroom. He went on to say that, although his broadcast education was not diverse, he "was instantly exposed to diversity and inclusion within the media workplace, while the majority of the media industry was still lagging behind."

Another participant stated that he did not fault the program he was in for not having more materials reflective of his background, but rather sees it as a reflection of Canadian media: "As an indigenous person, not a lot of the specific things that we studied related directly to me. It was good to learn how to do the job but with specifically covering my background, I did not see a lot of that. But I think that is an inherent problem in Canadian media to begin with, especially back then. I don't necessarily fault the program for that though. I fault the industry because I think the Canadian media has played catch up when it comes to covering indigenous issues".

Another interviewee echoed the sentiment that the root of this problem is found in the media and not in the educational institutions: "I am one of only a handful of women who work in the same field that I do. From my experiences, there are a lot of women taking broadcasting education courses but that same number is not being translated into the employment field, which I think may relate to the differences in income. Women in the field are still making significantly less than men, which creates issues among the employment. With that being said, the lack of women in the field is not necessarily a direct impact of the education but of issues within the field itself."

This participant was not the only one who brought up issues concerning women working in broadcast. Both male and female participants discussed several concerns, however, the issues surrounding pay and the fact that there are significantly less women working in Canadian media, especially in technical positions, were the most prominent.

One interviewee mentioned the fact that many of the guest speakers that came into her media classes to speak to students were male and Caucasian. She identified meeting guest speakers from diverse backgrounds as an important issue as it has a reverberating impact on future broadcast professionals. She stated, "You don't see yourself filling the same shoes as that person who is a guest speaker and so the idea of working in broadcast becomes less possible".

In another interview, it was mentioned that guest speakers are very important for broadcasting students for not only networking possibilities but also for providing a glimpse into the world they are trying to become part of. But as stated by one interviewee, it becomes difficult to connect with someone you do not have much in common with.

These two comments were significant as the survey given to broadcast educators had a statement on whether the broadcast/media industry professionals being invited to talk to students in the classrooms were from a range of backgrounds. Forty-three per cent of those surveyed indicated that the question was not applicable, leading to the belief that guest speakers are not coming into their classes. As well, only one of the interviewees mentioned bringing guest speakers in the classroom.

The broadcast professionals were asked, as well, to reflect on how inclusive teaching in broadcast education impacts the Canadian media landscape. All of the participants stated that they felt that inclusive teaching techniques in the classroom would influence students who consequently carry those lessons into the workplace. One participant said, "Since the broadcast industry is very subjective, I believe every producer that chooses their stories for their lineup will be based upon their experience. Every shot chosen by the reporter and editor is based upon their knowledge and what they believe to the best way to portray their story. How a writer uses their words to get across the point is based upon what they have learned to be the most effective way to do so. Since most people go to school prior to getting a job in the broadcast industry, what students learn in school and how they learn will make an impact on their job in the future and on the broadcast industry itself."

Another participant felt that inclusive teaching techniques can definitely shape the way stories are told in the media: "I think people who work in the industry now try to be as diverse/reflective as possible but it may not necessarily be ingrained yet. People are still most comfortable talking to people like them, that is just human nature. But I think if it is taught at the most fundamental level then there will be better journalism coming out of those teachings." 
Another interviewee stated his beliefs on the benefits of an inclusive environment in a classroom: "I believe that students can and will connect with their course materials that are pertinent to them and will feel morel comfortable in the classroom environment to voice their ideas/thoughts/questions. They are also more likely to experience achievement in their course through activities that support their learning styles, abilities, and backgrounds."

\section{Discussion}

All of the broadcast educators interviewed for this project, and more than $70 \%$ of those surveyed, indicated that they were employing inclusive teaching techniques in their classrooms, however, seven out of the eight broadcast professionals interviewed, whose graduate dates spanned 30 years, stated that more should be done in terms of diverse teaching in broadcast/media programs. As well, the data from this short research project seem to indicate that both broadcast educators and broadcast professionals believe that inclusive teaching in broadcast education has a positive impact on the Canadian media landscape in terms of diversity. Although some of the interviewees felt that the media itself was at fault for the type of broadcast education they had experienced, the fact is that most broadcast educators worked or still work in Canadian media and are bringing their experiences from the real world into their classrooms. This area definitely merits further research to determine the ebb and flow of influences between the Canadian media and broadcast education in Canada.

As this was a short project with a small sample, it is suggested that a sustained research endeavour, over a longer period of time and with more participants would be beneficial in expanding on the findings from this particular project. As well, having more qualitative data to analyze might clarify interesting points brought up by the interviewees that definitely deserve further reflections.

One such point was the fact that the number of women graduating from broadcasting programs is not translating into the workforce as mentioned by some interviewees. Questions arising from this point are: What are the factors impeding women from working in the media industry after graduating? Why are women in particular not pursuing technical positions in broadcasting? As well, if there are less women working in broadcast in Canada, what impact does that have on the media industry?

Another interesting point was the role that guest speakers play in broadcast education, as mentioned by some of the interviewees. Looking into the impact guest speakers from diverse backgrounds have on the representation of diversity in Canadian media might be an area of interest when researching inclusive teaching in broadcast education. As well, the fact that the intense nature of broadcast may impact the delivery of inclusive education in classrooms teaching broadcasting/media, as two broadcast professionals noted, merits further investigation.

\section{Limitations}

This project was completed in a span of six months, and, although I had a research assistant for three of those six months, I feel the project would have benefitted from a longer period of data collection as obtaining REBs at various institutions and finding participants from across Canada was a time consuming process. As aforementioned, I felt it would be challenging to find broadcast educators to interview, as the time period this project ran coincided with institutions' winter semester which runs between January and April. The winter semester tends to be the busiest for broadcast educators as they prepare their students for placements and consequently graduation. Having a lower than expected number of broadcast educators to interview and completed surveys resulted in less data to analyze and therefore the findings should be viewed with those numbers in mind.

As this was intended to be an exploratory research project with the intention of seeing where the data leads, I am hopeful that it can serve as a springboard to larger research projects in the areas of inclusive teaching in broadcast education and the representation of diverse groups in the Canadian media landscape.

\section{References}

[1] Saunders, S., \& Kardia, D. (2013) 'Creating Inclusive College Classrooms', University of Michigan; http://www.crlt.umich.edu/gsis/f6 (11 May 2013).

[2] Statistics Canada. (2013) 'National Household Survey (NHS)', Government of Canada;

http://www12.statcan.gc.ca/NHS-ENM/index-eng.cfm (12 May 2013).

[3] Carleson, K. B. (2012). 'New Poll Reveals Landscape Of Gay Canada', National Post; http://news.nationalpost.com/2012/07/06/the-true-northlgbt-new-poll-reveals-landscape-of-gay-canada (11 May 2013).

[4] Chambers, T., Sukai, M. and Bolton, M. (2011) 'Assessment of Debt Load and Financial Barriers Affecting Students with Disabilities in Canadian Postsecondary Education - Ontario Report'. Toronto, Higher Education Quality Council of Ontario.

[5] Statistics Canada. (2012) 'Women and Education', Government of Canada; 
http://www.statcan.gc.ca/pub/89-503-

x/2010001/article/11542-eng.htm (12 May 2013).

[6] Justice Laws Website. (2013) 'Broadcasting Act', Government of Canada; http://laws-lois.justice.gc.ca/eng/acts/B-9.01/FullText.html (12 May 2013).

[7] Little, D. (2004) Teaching a Diverse Student Body, University of Virginia, Charlottesville.

[8] Benick, G. (2012) 'Digital Storytelling and Diasporic Identities in High Education', Collected Essays on Learning and Teaching (6), pp.147-152.

[9] Schwieger, F., Gros, E., \& Barberan, L. (2010) 'Lessons From the Culturally Diverse Classroom: Intellectual Challenges and Opportunities of Teaching in the American University', College Teaching, 58 (4), pp. 148-155.

[10] Fleras, A. (2011) The Media Gaze: Representations of Diversities in Canada, UBC Press, Vancouver.

[11] Davis, C. H., Shtern, J. \& Silva, P. (2012) 'Roundtable on Cultural Diversity in the Toronto Screen Media Production Industry', Ryerson University, Toronto.

[12] Media Smarts (2011) 'Diversity in Media', http://mediasmarts.ca/diversity-media (10 May 2014).

[13] Media Action Média (2011) 'Representations of Diversity in Canadian Television Entertainment Programming: Case Studies', http://www.media-actionmedia.com/wp-content/uploads/2012/05/MAM_DiversityResearch-Report_FINAL.pdf (12 June, 2013).

[14] Johnson, R.B., \& Onwuegbuzie, A.J. (2004) 'Mixed methods research: A research paradigm whose time has come', Educational Researcher, 33 (7), pp.14-26.

[15] Adler, E. \& Clark, R. (2011) An Invitation to Social Research: How It's Done (4th Ed.), Thomson/Wadsworth Publishing Co, California.

[16] Jones, M, Kriflik, G \& Zanko, M. (2005) 'Grounded Theory: A theoretical and practical application in the Australian Film Industry', University of Wollongong; http://ro.uow.edu.au/commpapers/46 (13 May 2014). 